\title{
TECNOANTRHOPOSO EL \\ TRABAJADOR-SOLDADO GUERRA, TÉCNICA Y DOMESTICACIÓN HUMANA EN LA OBRA DE ERNST JÜNGER (1920-1933) ${ }^{1}$
}

\section{Tecnoantrhopos o trabalhador-soldado Guerra, técnica e domesticação humana na obra de Ernst Jünger (1920-1933)}

Diego P. Roldán²

\section{Resumen}

Este trabajo analiza las ideas que Jünger promovió en tomo a la técnica y cómo éstas se vinculan con la experiencia de la Guerra y a su idea de sujeto encarnada en El Trabajador. La intención es visualizar las formas en que Jünger propone una relación no contradictonia y optimista entre El hombre y la técnica. Se auscultará la tradición del pensamiento alemán fin de siècle, buscando comprender su relación con las transformaciones económicas, sociales y políticas que embargaron a Alemania entre fines del siglo XIX, pasando porla experiencia de la Primera Guerra Mundial y la desintegración de la República de Weimar. El estudio sostiene que esta clave de lectura brinda la posibilidad de entender el pensamiento de Jünger en una malla interpretativa compleja, idónea a al hora de extender sus posiciones dentro del pensamiento alemán políticamente conservador, pero, al mismo tiempo, entusiasta defensor de los avances tecnológicos. Finalmente, se investiga cuáles son las ideas de técnica, sujeto y verdad que sustentan las argumentaciones de Jünger en su obra publicada durante 1920-1933.

Palabras clave: Técnica; Primera Guerra Mundial; Romanticismo; Conservadurismo; Alemania

1 Agradezco especialmente los comentarios y el aliento para publicar este trabajo del Dr. Daniel Omar Pérez. También un reconocimiento especial merece el Prof. Jorge Morales Aimar, quien me introdujo en la obra de Enrst Jünger, al que debo muchas ideas expuestas en este trabajo y, en especial, deseo reconocer sus entusiastas comentarios sobre mis aproximaciones a la obra del escritor alemán. También ha sido de gran ayuda la lectura que el Dr. Darío G. Barriera efectuó sobre los borradores. Cecilia Pascual ha contribuido al enriquecimiento de las formas de este trabajo. Como siempre en estos casos, no debe atribuírseles a ellos las imperfecciones que este artículo pueda contener.

2 (UNR-CONICET) - Facultad de Humanidades y Artes. Universidad Nacional de Rosario - Consejo Nacional de Investigaciones Científicas y Tecnológicas

E-mail :diegrol@hotmail.com 
Este trabalho analisa as idéias que Jüngerpromoveu em to mo da técnica e como está se vinculando com a experiência da Guerra e sua idéia de sujeito encamada em $\mathrm{O}$ Trabalhador. A intenção é visualizar as formas em que Jünger propõe uma relação não contraditória e otimista entre O homem e a técnica. Se sondar a tradição do pensamento alemão fin de siècle, buscando compreender sua relação com as transformações econômicas, sociais e políticas que embargaram a Alemanha no final do século XIX, passando por experiência da Primeira Guerra Mundial e a designação da República de Weimar. $O$ estudo sustenta que esta chave de leitura brinda a possibilidade de entender o pensamento de Jünger em uma mala interpretativa complexa, idônea, a hora de estender suas posições dentro do pensamento alemão politicamente conservador, mas ao mesmo tempo entusiastas defensores dos avanços tecnológicos. Finalmente, investigam-se quais são as idéias técnicas, sujeito e verdade que sustentam as argumentações de Jüger em sua obra publicada durante 1920-1933.

Palavras-chave: Técnica; Primeira Guerra Mundial; Romantismo; Conservadorismo; Alemanha.

\begin{abstract}
"Si estabamos en buenas relaciones con el chofer, entonces nos permitía, dentro del garaje, sentarnos frente al volante de los vehículos. Fueron mis primeras impresiones de una embriaguez técnica en un mundo que a penas si comenzaba a ser gobernado por la tecnología. Sólo cuando después viví años en la prisión de Spandau como un hombre del siglo XIX, sin radio, televisión ni automóvil, cuando incluso no podía tocar siquiera el interruptor de la luz eléctrica, volví a sentir una felicidad parecida al poder utilizar años después de la prisión una enceradora de suelos eléctrica."
\end{abstract}

Albert Speer ${ }^{3}$

3 SPEER, Albert Memorias. Hitler y el Tercer Reich vividos desde dentro. Barcelona: Plaza y Janes, 1974, p. 18. Albert Speer fue el arquitecto más vinculado al poder político durante el III Reich. 
Introducción

Ernst Jünger (1895-1998) fue testigo privilegiado del siglo XX. En la pasada centuria probablemente emergieron los adelantos tecnológicos más impresionantes de la historia de la humanidad, durante los años 1960s. se rotuló a esta serie de asombrosos descubrimientos como Revolución Científico Técnica(BERNAL, 1965; RICHTA, 1971, POTER; TEICH,1990). En ese marco algunos intelectuales sucumbieron a la seducción de las utopías automatizadoras, que en sus visiones optimistas implicarían el fin de la sociedad de trabajo (GORZ, 2001). Cabría preguntarse si este proceso determinaría la muerte de El Trabajador imaginado por Jünger hacia 1932 y representado por una variante paradójicamente liberadora del Mito de Sísifo. El planteo de Jünger parece sugerir que la utilización simbiótica de la tecnología por parte del trabajador redimiría a éste de la vieja alienación, propia del trabajo propiciado en el entorno "decadente" de la civilización burguesa. Precisamente, Jünger ha sostenido, a lo largo de su extensa y variada trayectoria, que la técnica era un componente crucial de la cultura occidental, preocupación que heredó de Oswald Spengler y de su propia experiencia en el frente durante la Primera Guerra (SPENGLER, 1947).

Aún a sus cien años (1995), Jünger relataba que sus experiencias con el cine, creado el mismo año de su nacimiento, y las comunicaciones telefónicas implicaban para él algo más que la manipulación de un medio técnico instrumental para un fin social determinado. Según el escritor alemán, tanto el cine como las charlas telefónicas poseen un excedente vital que va más allá de la noción instrumental de tecnología y que se proyecta hacia un territorio dominado por la magia. Esta entidad mágica y fantasmática que, según Jünger, caracteriza a la técnica ha cautivado su atención en varios ensayos. Jünger ha aclararado que sus libros de juventud, aparentemente hegemonizados por una reflexión sobre la guerra (en particular la Primera Guerra Mundial), no son otra cosa que el preámbulo a su preocupación fundamental: el problema de la técnica.

Este estudio se consagra a comprender las orientaciones que Ernst Jünger produjo en torno a la técnica. En tal sentido, dividiremos el argumento en tres partes. La primera está destinada a revisar la tradición alemana del siglo XIX y principios del XX, considerando fundamentalmente el papel que el tardío, pero vertiginoso, acoplamiento de Alemania al capitalismo mundial deparó para la cultura y los intelectuales ale-

Revista e Filosofia,v. 18 n.22, p. 111-146, jan./jun. 2006 
manes. Es decir, reflexionaremos en torno a las oposiciones binarias que caracterizan al pensamiento social alemán decimonónico Gemeinschaft y Gesellschaft, Kultur y Zivilisation tomándolas como testigos de los acelerados procesos de modernización e industrialización que cercaron las antiguas tradiciones alemanas de fines del siglo XIX. Del mismo modo, concentraremos nuestra atención sobre la Guerra de 1914, momento que desempeñó un papel peculiar en el desenvolvimiento del pensamiento alemán. Es precisamente entre 1914 y 1918 cuando el conservadurismo alemán consiguió reconciliar, haciendo de necesidad virtud, las experiencias tecnológicas e industriales de nuevo cuño con unas formas de reflexión social y cultural que mantienen sus raíces hundidas en tradiciones elitistas, aristocráticas, pero sobre todo anti-burguesas y anti-iluministas. Finalmente, repararemos en la obra de Ernst Jünger, enmarcándola en este doble juego de configuraciones sociales y culturales que planteamos anteriormente, para luego proceder a realizar un análisis interno de sus trabajos. En particular, resulta relevante estudiar algunos de sus ensayos producidos durante la inmediata posguerra resumidos en el diario novelado en el que narra su experiencia en el frente: Tempestades de acero. Su ensayo La Movilización Total, escrito al filo de la crisis de 1929, reinterpreta con mayor perspectiva la I Guerra Mundial y plantea algunas pautas para el futuro de Alemania. Por último, El Trabajador. Dominio y figura aparece casi simultáneamente al alumbramiento del III Reich (1933) y constituye la obra más compleja de autor.

\section{Alemanha fins de siècle. Las antinomia de una "modernización peculiar"}

Luego del ciclo revolucionario 1789-1848, el capitalismo se exhibía consolidado en Europa, al menos, con toda seguridad en Inglaterra y Francia. La fase económica 1848-1873 fue relativamente estable, sin embargo en 1873 se alcanzó un punto crítico. El crecimiento de las ganancias se había detenido, Europa alumbraba la primera crisis capitalista que no se combinaba con elementos de la economía feudal y cuyas dimensiones alcanzaban la escala continental. La economía europea se habría tornado escasamente rentable en el período 1873 y 1896, a no ser por la conquista de nuevos mercados ultramarinos penetrados por el capital de las naciones europeas más consolidadas, fundamentalmente Inglaterra y 
Francia. Otras alternativas fueron ensayadas por los países menos favorecidos en el reparto del mundo, establecido por las potencias durante la fase imperialista del capitalismo. Entre ellas podemos contabilizar los ensayos de Alemania que comenzó a vincularse tardíamente al capitalismo, pero lo hacía a través de los medios tecnológicos más dinámicos propulsados por los rubros que dominaron la segunda fase de la Revolución Industrial: acero, electricidad y química. Atrás habían quedado el algodón, el hierro y el carbón que animaron la primera fase de la revolución industrial, indiscutiblemente liderada por Inglaterra.

El capitalismo ancló en Alemania a partir de una variante desconocida en el resto de los países Europeos, hecho que prestó un tono particular a su historia nacional (Sonderweg). Primero en Prusia y luego en Alemania, el Estado patrocinó las inversiones y dirigió relativamente los flujos de capital controlando los rubros estratégicos. Los antiguos terratenientes (Jünkers) fueron convertidos al credo del progreso y colaboraron con la burguesía alemana en la "alianza del cereal y el acero". Los grupos tradicionales retuvieron en sus manos los resortes del poder político y confirieron a los nuevos hombres de negocios el dominio del comercio, que podía completarse, en algunos casos, por el prestigio social dimanado del campo cultural y de la imbricación de las universidades alemanas con la formación de cuadros burocráticos (MAYER, 1986, p. 252). ${ }^{4}$

Durante la segunda mitad del siglo XIX, el desarrollo industrial alemán fue vertiginoso, las transformaciones que emergieron de semejante proceso modificaron de manera radical la percepción de los intelectuales alemanes del mundo circundante (Weltanschaug)(LÖWY, 1978, P. 31). ${ }^{5}$ Los intelectuales vinculados a las humanidades de viejo cuño, y, por tanto, a un mundo que tendía a enfatizar valores cualitativos, se sintieron cercados por el avance de un universo cada vez más calculable,

4 "Los creyentes en el evangelio del progreso terrenal procedían sobre todo de la burguesía empresarial y profesional racionalista y de la clase media educada. Pero el antiguo orden seguía demasiado intacto para que el nuevo credo tentase a las élites dominantes terratenientes, de la administración pública y de la cultura, o para adquirir muchos conversos entre el campesinado, la petite bourgeoisie y las masas obreras.".

5 "En la producción de acero, Alemania, que estaba atrás de Francia y mucho más atrás que Inglaterra en 1860, produjo en 1910, más acero que estas dos naciones juntas. A principios de siglo, Alemania se transformó, de país "pobre" y semifeudal, en la segunda potencia industrial del mundo, después de Estados Unidos." 
donde todo podía transformarse en mero valor de cambio. Convertir todo bien material o cultural en una "cosa" que puede ser cambiada en el mercado, hace de la compleja experiencia cualitativa e irreductible del mundo un ámbito conquistable por la abstracción reificadora del cálculo. En este marco algunos intelectuales se revelaron y, en particular, apelaron a un rechazo del capitalismo que adquirió un carácter visceral en Alemania, probablemente por la extensa raigambre de la tradición idealista y romántica.

Frente al desarrollo del capitalismo, que reduce al hombre cada vez más a una dimensión abstracta, calculable, que instaura un sistema racionalista rigurosamente cuantitativo, el romanticismo define como pasión las formas concretas, cualitativas e intuitivas del pensamiento y de la vida, las relaciones humanas personales y concretas que permanecen vivas en las capas precapitalistas [... ] Las viejas tradiciones, estilos de vida y comportamientos, sociales negados por racionalismo capitalista abstracto, son ideológicamente rehabilitados y restaurados por los románticos (LÖWY, 1978, p. 25).

Las obras de Schopenhauer y Nietzsche pueden ser consideradas como puentes que se tienden entre el viejo romanticismo, al cual rinden cierto tributo - aunque modifican varios de sus temas-, y sus nuevas vertientes aparecidas durante el período 1880-1918. Friedrich Nietzsche fue un crítico acérrimo del maquinismo, de la división del trabajo, de la destrucción de la pequeña producción artesanal, de la despersonalización de los individuos y del crecimiento de las grandes ciudades industriales en todo esto podría identificarse con un romántico. Sin embargo, su implacable crítica de la Iglesia, su ética y estética individualista del superhombre y su desprecio de lo colectivo plantean al autor de El Anticristo como un pensador post-romántico (MANN, 1990). También su desdén por la tradición ilustrada y las formas democráticas lo colocaron en las antípodas de la fase revolucionaria del romanticismo, cuya producción puede datarse en torno a los años 1830 y 1848 (MAYER, 1986,p. 263). ${ }^{6}$

6 “... las aspiraciones democráticas eran la principal maldición de los tiempos modernos [... ] los animales del rebaño se convertían en amos. Nietzsche denunciaba a Rousseau por ser el "idealista y canaille" que había infundido a la revolución una 'moral y una doctrina de la igualdad' que era 'el más tóxico de los venenos'. Además, Nietzsche agregaba que la democracia era "el absurdo de los números" y "la superstición de las mayorías". 
Entre 1879 y 1914 Alemania se transformó en una nación altamente industrializada, el proceso de modernización puede calificarse como rápido, intensivo y hasta brutal. Los intelectuales fueron violentamente traumatizados por el incuestionable imperio del capitalismo. Su reacción contra el triunfo de "la sociedad sin alma" fue equivalente en causticidad a la intempestiva industrialización alemana. Los núcleos culturales compartieron un cierto horror hacia una época dominada por el materialismo, la vorágine industrial, la estandarización y el carácter superficial y efímero de todo lo humano (BERMAN, 1989).

Las grandes concentraciones humanas alarmaban a los intelectuales que las percibían como un signo de la inequívoca decadencia de la cultura europea. El crecimiento repentino de "ciudades sin espíritu" inquietaba tanto a los intelectuales como la degradación de las antiguas ciudades europeas que concentraban al mundo cultural de Europa. La metrópolis fin de siècle era la fiel representante del mundo capitalista que le había dado vida, precisamente allí se localizaba el reino del cálculo, un ambiente donde las relaciones individuales estaban reificadas e instrumentalizadas por la mediación del dinero.

Las grandes ciudades han sido desde tiempos inmemoriales la sede de la economía monetaria, puesto que la multiplicidad y la aglomeración del intercambio económico proporciona al medio de cambio una importancia a la que no hubiera llegado en la escasez del trueque campesino. Pero economía monetaria y dominio del entendimiento están en la más profunda armonía. Les es común la pura objetividad en el trato con los hombre y las cosas [...] El hombre puramente racional es indiferente frente a todo lo auténticamente individual [...] Pues el dinero sólo pregunta por aquello que es común a todos, por el valor de cambio que nivela toda cualidad y toda peculiaridad sobre la base de la pregunta por el mero cuánto. Todas las relaciones anímicas entre personas se fundamentan en su individualidad, mientras que las relaciones conforme al entendimiento calculan con los hombres como con los números, con elementos en sí indiferentes que sólo tienen interés por su prestación objetivamente sopesable; al igual que la urbanita calcula con sus proveedores y sus clientes, sus sirvientes y bastante a menudo con personas de su propio círculo social, en contraposición con el carácter del círculo más pequeño, en el que el inevitable conocimiento de las individualidades produce inevitablemente una coloración del comportamiento plena de sentimiento, un más allá del sopesar objetivo de prestación contraprestación (SIMMEL, 1988, p. 298). 
Este párrafo de Simmel fechado a principios del siglo XX, fue largamente preparado por una nueva versión del romanticismo anticapitalista que surgió en Alemania a fines del siglo XIX. El estandarte de esta corriente fue la oposición Kultur y Zivilisation. La Kultur era la esfera dominada por los valores éticos, estéticos y políticos, un estilo de vida personal, que apelaba al universo interior, natural y orgánico propiamente alemán; la Zilvilisation, por el contrario, aludía al progreso material, técnico, económico, exterior, mecánico, artificial y al rebuscamiento (afeminamiento) de las sociabilidades, los orígenes de ambos eran ingleses y franceses, respectivamente. ${ }^{7}$ Esta antinomia fue transferida al plano sociológico por Ferdinand Tönnies en su Gemeinschaft und Gesellschaft (Comunidad y Sociedad) publicado originalmente en 1887. Esta obra inspiró a toda la sociología alemana hasta la década de 1930. Es notable que el trabajo de Tönnies recuperaba aquellas oposiciones binarias a partir de una experiencia vital. ${ }^{8}$

El planteo de Tönnies opone dos universos socioeconómicos de manera abstracta, como si se tratara de dos tipos de relaciones socioculturales; de este modo, comunidad y sociedad constituyen la base de un principio de estructuración social que se encuentra en la subjetividad individual: la voluntad esencial domina en la Comunidad y la voluntad arbitraria prevalece en la Sociedad. Según Tönnies, el universo comunitario (familia, pueblo, pequeña aldea tradicional) está reglamentado por hábitos, costumbres y ritos. El trabajo dentro del pequeño poblado es motivado por el placer y el amor a la producción, que se manifiestan en la organización de una economía agrícola y artesanal. Además, las relaciones sociales se caracterizan por la ayuda mutua y la totalidad es regida por la Kultur (religión, arte, moral y filosofía). En contrapunto, el mundo de la sociedad (la gran ciudad, el estado nacional, etc.) es anima-

7 Sobre el surgimiento y los caracteres de la oposición Kultur / Zivilisation en la cultura alemana ver: ELIAS, Norbert "Sociogénesis de la oposición entre «cultura»y «civilización»en Alemania", en: El proceso de civilización. Investigaciones sociogenéticas y psicogenéticas. México: Fondo de Cultura Económica, 1989, pp. 57-94.

8 Tönnies nació en 1855 en una granja de pequeños agricultores en Schleswing-Hoplstein, pasó toda su infancia en el campo y luego de la jubilación de su padre en una pequeña ciudad marítima, llamada Husum perteneciente a la misma región. Por vía materna descendía de una familia de pastores protestantes. Es decir, sus herencias y la mayor parte de su existencia estaban relacionadas con la vida comunitaria y rural que el capitalismo alemán comenzaba a desbaratar, con su reemplazo de las tradicionales cosechas festivas por las ciegas mecanizadas e indiferentes. 
do por el cálculo, la especulación, la utilidad. Entonces, la ganancia es el único objetivo del trabajo y de la industria moderna. El hombre en su actividad fundamental es degradado a la condición de simple medio de comercio. La vida social en las grandes ciudades se encuentra desgarrada por el egoísmo y la guerra hobbesiana de todos contra todos, en el marco del desarrollo constante e irreversible de la Zivilisation (progreso técnico e industrial)(TÖNNIES, 1947).

En Comunidad y Sociedad se muestra claramente que el cálculo achata la vida (entendida como experiencia cualitativa) y por lo tanto agota la fuente misma de la moralidad. No obstante, si bien este planteo contiene un gesto nostálgico respecto al orden antiguo, acepta el hecho irrevocable del advenimiento del capitalismo. Es un conservadurismo que asume la modernidad como un camino sin retorno, una metáfora cuyo mayor o menor pesimismo respecto al progreso técnico tuvo varios epígonos en el pensamiento alemán de fines del siglo XIX y principios del XX.

... la sociología alemana hace eco a las preocupaciones angustiosas que han sido centrales en las teorías sociales y políticas del conservatismo romántico [... [ [aunque] no era agraria ni feudal en su orientación, porque no tenia lazo con la aristocracia terrateniente. Un sentido de resignación era típico de esta teoría social 'adaptacionista'. Los modernistas al contrario de sus colegas ortodoxos comprendían que no había escapatoria total a la modernidad. Podían hacer frente a los hechos, aceptar ciertos aspectos de la vida moderna como inevitable (LÖWY, 1978p. 35).

Puede apreciarse, entonces que Filosofía del dinero, publicado en 1900 y firmado por Georg Simmel, hundía sus raíces en una tradición alemana conservadora que a un solo tiempo asumía la imposibilidad de volver al antiguo orden y se mostraba crítica respecto a los desarrollos del capitalismo (SIMMEL, 1977, p. 661). El propio Max Weber con su fórmula de la "jaula de hierro" formaba parte de este conglomerado de pensamiento. No obstante, este corpus de ideas matrizado por la oposición Kultur / Zivilisation fue, como todo en Alemania, violentamente sacudido por el impacto de la Primera Guerra Mundial. Las antinomias del campo intelectual serían retrazadas por las novedades tecnológicas de la industria de la muerte. Tras la derrota de 1918, los pensadores conservadores alemanes comprendieron que Alemania debía ser simul- 
táneamente un Estado tecnológicamente avanzado y fiel a su espíritu si quería sobrevivir en la lucha por el poder internacional. Por lo tanto, en adelante, el desarrollo tecnológico fue indisociable de la necesidad de un Estado fuerte y competitivo en tanto potencia internacional. Las visiones decadentistas de la historia gananían la palestra, abandonando para siempre su tradicional dandysmo y misticismo e ingresando en un proceso de paulatina politización. La publicación de uno de los libros más influyentes de la época, al menos en el campo del pensamiento conservador: La decadencia de occidente (1918) cumplió un rol mayúsculo en este proceso.

\title{
La gran guerra: el progresso y la técnica al servicio de la destrucción y el exterminio
}

\begin{abstract}
“... el sentimiento alemán respecto a la naturaleza recibió un empuje inesperado. Los duendes de la paz que tan sensiblemente lo habitaron fueron evacuados y, mirando en derredor desde el borde de la fosa, se extendía el campo del idealismo alemán. [...] la técnica intentó mover los hilos del heroísmo con lanzallamas y trincheras [... ]la guerra que los nuevos nacionalistas conciben como abstracción metafísica se reduce en última instancia, al intento de resolver en el ámbito de la técnica, mística y espontáneamente, el secreto de una naturaleza ideal, en vez de emprender el rodeo que, desde una perspectiva de los asuntos humanos significaría la evolución del empleo de la técnica y de las clarificaciones que pudiera aportar."
\end{abstract}

(BENJAMÍN, 1991, p. 55)

En 1901, el exitoso empresario alemán, Fritz Krupp, patrocinó un concurso que premiaba al mejor ensayo sobre las posibles aplicaciones de la teoría de Charles Darwin al gobierno del pueblo alemán. Ernst Haeckel, inventor del término ecología y autor de una teoría monista de la evolución, fue convocado para integrar el jurado del mentado certamen. ${ }^{9}$ Eran tiempos de confrontación entre lamarkismo y darwinismo,

9 La teoría monista de la evolución propuesta por Haeckel equiparaba al hombre a la naturaleza, negaba la posibilidad de que éste pudiera escapar a las leyes naturales. Semejante concepto facilitaba la traslación del estudio de los fenómenos naturales a los culturales o sociales. Así, el contexto social donde se desplegaba la acción humana no tenía ninguna incidencia sobre el rumbo de la evolución. 
en este marco varias cuestiones apremiaban el desarrollo de la ciencia biológica: ¿El medio social influía o no en el curso de la evolución? ¿El orden biológico respondía a las transformaciones sociales o era autónomo respecto a éstas? Tras estas preguntas, procedentes del paradigma de la "ciencia positiva” (neutral, objetiva y aséptica en términos ideológicos), se ocultaba una preocupación política: ¿era aconsejable la reforma social? Y si lo era, cuáles serían las mejores fómulas para llevarla a cabo (ANDREASSI CERI, 2004).

.La memoria ganadora fue firmada por Wilhelm Schallmayer y llevaba el título de Veretbung und Auslese (Herencia y Selección), sus principales argumentos se colocaban en la línea trazada años atrás por Haeckel. Afirmaba que el principio de selección natural establecido por Darwin era la condición necesaria para toda mejora en el plano social, el progreso oficiaba como una variable de proporcionalidad directa respecto a la selección. En este estudio se negaba cualquier resabio de lamarkismo, el ambiente tenía una escasa capacidad para la determinación del curso evolutivo. Este razonamiento indicaba que podía actuarse sobre los problemas de Alemania sin recurrir a la reforma social. Además, los argumentos de Schallmayer daban nuevos fundamentos a los planteos de la vieja Gemeinschaft, proclamada por Tönnies en 1887. A juicio del ensayista la vitalidad de un pueblo dependía, básicamente, de la voluntad que expresara cada uno de los individuos que componen el Volk, sin embargo esta vitalidad debía subordinarse a los objetivos de la comunidad y sólo en esa sujeción podía hallar el camino para la realización de su propia finalidad. En otros términos, la libertad individual era accesible únicamente a partir de la más estricta subordinación al conjunto colectivo. La vida del hombre (individuo) era comparable a la de una célula incluida dentro del organismo, no sería nada excluida o aislada del todo en el que se hallaba inevitablemente integrada. La parte era, entonces, inseparable de la totalidad y la totalidad no podía funcionar correctamente prescindiendo de la parte, un racionamiento organicista con bases en la biología evolutiva. ${ }^{10}$

Por lo demás, Schallemayer rehuye a los criterios de selección natural basados en el laissez-faire planteados por el darwinismo social de tono "manchesteriano" (liberal), encarnado en la figura de Herbert Spencer. Si el autor de El individuo contra el Estado identificaba a la

10 Conviene retener este razonamiento para comprender mejor las formulaciones de Jünger con respecto al Trabajador y el binomio dominio-libertad que se expondrán en el apartado siguiente.

Revista e Filosofia,v. 18 n.22, p. 111-146, jan./jun. 2006 
"filantropía estadística" como una suerte de freno al desarrollo de las leyes darwinistas de supervivencia de los más aptos y preconizaba la prescindencia del Estado en materia económica, sus colegas alemanes coincidían con él en la no intervención del Estado orientada a ayudar a los más débiles, antes bien el Estado debía promover la aceleración del proceso de selección social (natural) positiva (SPENCER, 1984). De modo que los programas del Estado alemán estarían destinados a privilegiar la supervivencia de los más aptos y, por ende, a planificar la muerte de los menos dotados. Este proceso fue justificado por su mero carácter natural, según Haeckel no estaba en manos de los hombres de principios del siglo XX alterar las leyes de la naturaleza.

Podemos lamentar profundamente este trágico estado de cosas, pero no podemos discutirlo ni alterarlo. 'Muchos son llamados pero pocos elegidos'. La selección de esos 'elegidos' está conectada inevitablemente con la captura y destrucción de la mayonía restante (HAECKEL, 2003).

Con todo, el distanciamiento del pensamiento spenceriano no era absoluto. El principio fijado por Spencer sobre la centralización del control respecto a un sistema orgánico que guarda una relación directamente proporcional a la diferenciación, $\mathrm{y}$, por lo tanto, a la complejidad y superioridad del organismo, fue aplicado en Alemania para justificar la concepción jerárquica de la sociedad y la intervención del Estado como un organismo neutral, capaz de dirigir el proceso de selección social.

Esta preocupación por la ingeniería social que manifestaban los Krupp, representantes de un grupo industrial concentrado, se basaba en la idea de que si la sociedad funcionaba bajo el influjo de fuerzas ciegas similares a las de la naturaleza, el hombre al tomar conocimiento de esas leyes podría desarrollar mecanismos de control e inducción de la fenomenología social. Así, la homología simplista entre naturaleza sociedad quedaba soldada. El hombre había dominado a la naturaleza a través de la técnica, a principios del siglo XX tenía una nueva tarea, desarrollar una técnica destinada a dominar a la sociedad, entendida como una segunda naturaleza controlable a partir de los parámetros científicos de la física y de la biología. ${ }^{11}$ Por su parte, las ideas en torno a la supervi-

11 Dos obras, además de El origen de las especies (1859), son fundamentales en este período para comprender estas especulaciones sociológicas: Discurso sobreel espíritu positivo (1844) de August Comte y Curso de medicina experimental (1856) de Claude Bernard. 
Tecnoantrhopos o el trabajador-soldado guerra, técnica y domesticación humana en ...

vencia de los más aptos y el organicismo como modo de constitución social alcanzaron su apogeo continental y nacionalista durante la Primera Guerra Mundial.

Cabría agregar que este biologísismo se unió sin mayores contradicciones con el naturalismo de prosapia taylorista. En los argumentos del destacado ingeniero de Bethelms Works, semejante naturalismo emerge bajo las formas de un determinismo tecnológico, la absoluta autonomía de la técnica respecto de al voluntad humana. Así, también la técnica es asimilada a la naturaleza. Según Frederick Winsolw Taylor la necesidad de la realización del capitalismo se imponía y, al mismo tiempo, fijaba su mandato cifrado en una ciega obediencia para el hombre. Sólo había una manera optima de realizar una tarea, y ésta consistía en reducir a su mínima expresión la cantidad de movimientos que realizaba el operario (diminución de los tiempos de producción = aumento de la productividad). Sólo había que descubrir cuál era esa mínima expresión, tal la tarea del organizador científico del trabajo. De modo similar a las teorías de Haeckel, las ideas de Taylor impugnaban los fundamentos de la tradición ilustrada, particularmente el antropocentrismo, al negar la posibilidad de que el conocimiento dependiera de la unidad sujeto-objeto, al modo trascendental kantiano. Este hecho fue tempranamente visualizado por el escritor vanguardista Evgeni Zamiatin, en los primeros años de la Revolución Rusa. ${ }^{12}$

Pero, cambiemos la fábrica por el campo de batalla, troquemos, diría Jünger, un taller por otro, ingresemos al ambiente de destrucción creado por la Gran Guerra. Para muchos observadores la guerra implicó una especie de selección natural a escala europea, cantada, algunos años antes, por los poetas futuristas como la "sola higiene del mundo"(MARINETTI, 1909). Durante la Primera Guerra Mundial murie-

12 En su poco citada novela distópica Nosotros, Zamiatin construye un universo totalitario regulado por el taylorismo y el colectivismo imperante en la joven URSS, sus críticas se dirigen a las tendencias que pretendían instaurar la militarización del trabajo, aparecidas bajo los auspicios de Trotski durante las primeras etapas de la Revolución Rusa. La siguiente frase nos exime de toda explicación: "Cierto, ese Taylor fue le más genial de los antiguos [la acción se ubica doscientos años después de una hipotética Revolución Mundial]. Es verdad que no fue capaz de reflexionar sobre su idea como para aplicarla a toda la vida, a cada paso, a las veinticuatro horas; no supo integrar en su sistema todas las horas, de la una a la veinticuatro. Sin embargo ¿Cómo fue posible que se escribieran bibliotecas enteras sobre un Kant cualquiera y apenas notaran a Taylor, ese profeta que supo ver hasta diez siglos más adelante?' (ZAMIATIN, 1903, p. 29).

Revista e Filosofia,v. 18 n.22, p. 111-146, jan./jun. 2006 
ron trece millones de seres humanos y se trató, desde diversos puntos de vista, del acontecimiento fundador del siglo XX. Ernst Jünger, partícipe y analista, ha señalado que la técnica manifestó toda su potencia en la guerra mundial de 1914-1918, "la primera guerra de materiales." Se trató de un conflicto profundamente distinto de los anteriores, dado que el choque no se produjo solamente entre ejércitos sino entre potencias industriales (JUNGER, 1998, p. 21). En la guerra moderna (después de 1914) los países se transforman en grandes fábricas de armamento en cadena, que merced a veinticuatro horas de trabajo diarias enviaban al frente abastecimientos de todo tipo. La línea de fuego hacía la veces de un inmenso mercado de consumo, cuyo gasto se enmarcaba en un proceso sangriento y completamente mecanizado. El "espectáculo" de la guerra es "monótono", "recuerda el funcionamiento de una turbina alimentada con sangre humana. Es la manifestación de la época en que vivimos en el campo de batalla"(JUNGR, 1992, p. 8).

Esta nueva forma de guerra se basaba en el movimiento intensivo. Sus atributos no podían ser brindados por la sola acción de los seres humanos, se precisaba del auxilio de la técnica. Los sectores más dinámicos del frente de 1914-1918 fueron animados por barcos, aviones y tanques, máquinas diseñadas para el combate cuya intervención transformó perdurablemente las tácticas militares. No obstante, la Primera Guerra destruyó sólo parcialmente las antiguas formas de la contienda, aún no lograba dar con la nueva imagen de la guerra total. De cualquier modo, la aplicación de la tecnología al arte de al guerra fue la clave de la estrategia militar después de 1914, desde entonces aquel ejército que no se sometiera a los rigores de la mecanización sería inexorablemente derrotado.

La guerra se produjo durante la época de la sociedad de masas, del darwinismo elitista con proyecciones políticas y de la organización científica del trabajo, por lo tanto los soldados se transformaron en obreros tayloristas que producían muerte en el frente, del mismo modo que hubieran fabricado mercancías de haber estado frente a una cadena de montaje. La deshumanización de la fábrica proyectaba sus contornos más siniestros sobre el campo de batalla. El obrero no conocía ni podía controlar absolutamente la estrategia, sólo representaba a una milésima parte del autoritario despliegue total de tropas. El enajenamiento experimentado en el combate, ante la incertidumbre del resultado de las acciones, agudizaba la alienación de la fábrica en un escenario sembrado de 
horrores. En tiempos del obrero-masa y de la fábrica taylorista-fordista emergió como su partenaire necesario: el soldado-masa, despojado de toda peculiaridad y heroicidad. Este nuevo combatiente no sostenía luchas cuerpo a cuerpo, asesinaba sirviéndose en sus faenas, ya no de exquisitas armas cuidadosamente labradas, sino de máquinarias de exterminio a distancia, entre las que se destacaba la ametralladora. Este nuevo dispositivo mecánico ideado para exterminar al enemigo a partir de la repetición de disparos que prácticamente suprime el momento de recarga (nuevamente aprovechamiento intensivo del tiempo), produjo un profundo impacto entre quienes pudieron observarlo en funcionamiento. Para Jünger, las armas, al igual que la técnica, jamás juegan un rol neutral: "No existen armas en sí; la forma de cada arma la determinan tanto los sujetos que la portan como los objetos, los adversarios a que ella ha de herir"(JUNGER, 1992, p. 183).

Rodeado de medios técnicos e impotente ante sus comandos, el soldado moderno carecía del valor y la heroicidad individuales que habían forjado el aura del guerrero antiguo, tras su muerte, una desaparición sin gloria, se le dedicaron monumentos al "soldado desconocido", muestra cabal de su carácter anónimo, masivo y despersonalizado. La Primera Guerra asistió a "... la aniquilación definitiva de la vieja casta guerrera llevada a cabo por la batalla mecánica.” (JUNGER, 1992, p. 157).

En la profundidad de las trincheras, la muerte se transmutó en un espectáculo estandarizado, seriado, masivo, industrializado y banal (naturalizado). La guerra era una forma de exterminio industrial que trasvasaba las más disparatadas ensoñaciones de Carl Von Clausewitz( 1998). Los límites técnicos y morales de los antiguos enfrentamientos bélicos quedaron reducidos a añicos bajo el peso de las imágenes que se desprendían de paisajes devastados y ciudades bombardeadas. El año 1914 asistió a la apertura de una industria de la muerte, cuya fatigosa red de fábricas eran las trincheras. El hombre fue despojado de sus atributos individuales, reificado una vez más por la máquina que asesinaba a distancia, por otros soldados que no percibía a sus enemigos, pero igualmente acometían un exterminio abstracto e impersonal, más allá del odio, la emoción y la culpa. En definitiva, más allá del bien y del mal.

Los soldados se metamorfosearon en los milicianos del trabajo soñados por Ernst Júnger(1992, P. 144). ${ }^{13}$ Se trataba de una nueva raza,

13 Según Jünger el soldado anónimo es uno de los primeros representantes del tipo activo, que viene a destruir tanto al tipo burgués como al hombre masa y que denomina Trabajador".

Revista e Filosofia,v. 18 n.22, p. 111-146, jan./jun. 2006 
su figura había sido fraguada por el combate, su silueta asomaba fría, mecánica y amenazante del mar de fuego. Su rostro, estampado por la iconografía nacionalista de tono fascistizante, no podía distinguirse más allá de un conjunto de líneas cortantes que se fusionaban con su casco metálico. Su identidad era una mueca invisible provista de una enorme agresividad, un cierto nihilismo ${ }^{14}$ y una voluntad inflexible (JÜNGER, 1993).

El soldado, que había transformado su propio cuerpo en un aparato metálico y sus músculos en engranajes de acero que unían podery belleza, evocaba, en los códigos de la estética fascista, a un guerrero antiguo con su armadura. Un aura ancestral rodeaba al soldado de la guerra total modema, al 'miliciano del trabajo' que encarnaba el romanticismo tecnificado de la revolución conservadora (TRAVERSO, 2002, p. 109).

El darwinismo social y la organización científica del trabajo se celebraban mutuamente, se hallaban hermanados en una cruzada contra el humanismo. Bajo sus miradas selectiva y controladora el hombre caía prisionero en las mallas de las leyes de la naturaleza o en las cárceles de los imponderables de la tecnología. La guerra, con su ergonomía de las trincheras, funcionó como el catalizador de ambas, aunando sus tendencias deshumanizadoras en medio del exterminio serializado. Tras la derrota y en el sendero que abre la entreguerras para pensamiento reaccionario alemán, la tecnología y la naturaleza aparecieron hermanadas, asimiladas por el lenguaje poético. En esa labor tuvieron un papel central los variados escritos que Ernst Jünger consagró a la guerra, a la técnica y a ese ser disciplinado hasta lo inhumano por su relación con la tecnología, al que llamó El trabajador.

\section{La guerra como experiencia iniciática y el mito antropotécnico del trabajador-soldado}

La guerra me ha cambiado profundamente, como lo ha hecho estoy convencido, con toda mi generación [... ] su espíritu está entre nosotros, siervos de su mecánica, y de la que jamás podremos desembarazarnos. ... los acontecimientos se desarrollaban en medio de un fuego

${ }^{14}$ El nihilismo que exuda la batalla puede leerse en frases como esta: "vivir significa matar". 
infernal, alimentado por instrumentos de precisión [... ] relación esencial del trabajador con el mundo del trabajo, un mundo del cual el aludido paisaje de fuego es su símbolo bélico (JÜNGER, 1997, 1992)

Según Ferenc Feher y Michael Löwy, la Primera Guerra Mundial se convirtió en un punto de inflexión para el anticapitalismo romántico proclamado por los escritores alemanes, que hemos descrito en la primera sección de este artículo. A partir de entonces, el romanticismo derechista rechazó algunos tópicos que anteriormente le habían sido inherentes, particularmente fueron anuladas las críticas a la deshumanización provocada por la máquina. Así, en los años 1920s y 1930s., E. Jünger y C. Schmitt se jactaban de diferenciarse del romanticismo decimonónico, a pesar de que sus panegíricos del hombre nuevo, que nacía de la destrucción y de las muerte rodeada por el "desierto infinito de trincheras", ${ }^{15}$ constituían una antigua visión romántica aggiornada al siglo XX (HERF, 1998, p. 42-43). La guerra sin embargo era la experiencia que convertía el simbolismo de la máquina en una temática asimilable al romanticismo conservador.

Durante la República de Weimar, creada en 1918, dos corrientes literarias se erigieron como portavoces de la experiencia de la guerra. Una de ellas rememoró las batallas con fascinación y placer, ensalzando el ejercicio indiscriminado de la violencia desde un punto de vista estético; la otra narró los horrores del campo bélico con miras a efectuar una crítica de la barbarie, su planteo abrevaba en un humanismo pacifista. Representante de la primera tendencia fue el libro Tempestades de Acero de Ernst Jünger (1993) y de la segunda Sin Novedad en el Frente de Enrich-Maria Remarque (REMARQUE, 1985, 185p.).

Según Norbert Elias, no hay dudas de que la obra que con mayor calidad literaria exaltó la guerra en este período fue Tempestades deacero. Su autor no sólo describe la guerra en toda su crudeza sino que parece sentirse a gusto en medio del horror que se desprende de los enfrentamientos. En este diario novelado, Jünger presenta al soldado como un sujeto obligado a cumplir su deber con alegría (fórmula despojada de alienación que años después revivió para componer El Trabajador)(JÜNGER, 1992). El oficial Jünger se muestra habituado a matar y no escatima en detalles morbosos al presentar las sensaciones que despierta en su alma la muerte del enemigo. Cuidadosamente son

${ }^{15}$ JUNGER, Ernst “La Movilización Total”, cit., p. 11.

Revista e Filosofia,v. 18 n.22, p. 111-146, jan./jun. 2006 
omitidas todas las posibles referencias al temor, la vacilación y la angustia, signos inequívocos de flaqueza, debilidad y, peor aún, de ausencia de valor. Los oficiales acatan las ordenes sin importar las consecuencias, carecen de dudas y de escrúpulos morales, son la pura manifestación de la acción disciplinada. De este modo, Jünger glorifica el horror prestándole una atmósfera agradable y hasta honorable, establece un aura romántica que preserva de consideraciones piadosas o racionales al ejercicio indiscriminado de la violencia. Así aludida, la guerra adquiere un carácter cercano a la experiencia religiosa primigenia, que suelda y consolida la identidad colectiva de los hombres que combaten en el frente.

El éxtasis embarga a la tropa, la guerra se asemeja a un espectáculo de embriaguez colectiva, a una orgía báquica donde la sangre y el vino son fundidos por el fuego. La experiencia de la guerra en la prosa de Jünger se transforma en una substancia alucinógena, capaz de unificar a los hombres más diversos en un viaje extraordinario. ${ }^{16}$ No obstante, al igual que sostiene Baudelaire en Los paraísos artificiales, el estupefaciente de aglutinación sólo es efectivo si existe una experiencia previa compartida (BAUDELAIRE, 19-j. Un grupo de jóvenes nacidos entre 1885 y 1895 poseían una identidad previa a su inmersión en la trinchera, todos estaban hastiados del mundo burgués, de su falta de emoción, de sus seguridades pusilánimes y predecibles. Todos renegaban de ese imperio del cálculo individual que había sofocado a las pasiones colectivas. Si podían formar una comunidad se debía a sus experiencias comunes en el universo del burgués, el frente pone en acto y también acrecienta lo que ya era potencia.

El combate y la comunidad masculina de las trincheras muestran a un Jünger que se permite describir la experiencia de la guerra a través de metáforas religiosas y sexuales que remiten al ritual de fundación comunitaria, descrito por Émile Durkheim en Las formas elementales de la vida religiosa (DURKHEIM, 1912).

De nuevo: el éxtasis. La condición del hombre sagrado, de los grandes poetas y del gran amor se concede también a los hombres de gran valor. El entusiasmo de la hombría se desborda de tal manera que la sangre

16 Jünger a comienzos de los años 1950 y nuevamente 1971, convidó a Albert Hoffmann, quien en 1938 había sitetizado la dietilamina de ácido licergico, a experimentar con esta substancia escuchando música de Mozart. Estas experiencias fueron reunidas en Aproximaciones 
hierve al correr por las venas y brilla al circular por el corazón... Es una intoxicación que va más allá de toda intoxicación, una liberación que rompe todos los lazos. Es el frenesí sin cautela ni límites, sólo comparable a las fuerzas de la naturaleza. Allí [en el combate], el individuo es como una tormenta furiosa, el mar desbordado y el trueno retumbante. Se ha fundido en todo. Descansa en la puerta oscura de la muerte como una bala que ha llegado a su destino. Y las ondas púrpuras le pasan por encima. Durante largo tiempo, no tiene conciencia de la transición. Es como si una ola se arrastrara de regreso al fluyente mar (JÜNGER, 1997, p. 59).

El soldado se reconoce en la totalidad extática de la batalla. La guerra, para Jünger, constituye una experiencia interior, en tanto camino hacia uno mismo. Donde encontrarse implica hallarse en el todo, en una surte de panteísmo mágico que incluye a la tecnología.

En su juventud, Jünger había viajado a África como legionario para darle emoción a su vida, para apartarse de la chatura de la civilización burguesa, que incluía un padre intransigente. ${ }^{17}$ Ante semejante opción, es comprensible que el escritor alemán fuera devoto de la Fronterlebnis (experiencia del frente) vivida intensamente como la añorada liberación de la fría seguridad burguesa decimonónica. La guerra representaba un contacto fugaz con un mundo de excitaciones románticas y peligros intempestivos. El campo de operaciones era el lugar apropiado para el despliegue de las fuerzas exóticas y elementales que recordaban la virginidad del continente africano(HERF, 1998, p. 159). Por lo demás, la Gemeinschaft masculina de las trincheras era el legado de una conflagración total perdida por Alemania, se constituía en una opción reaccionaria de cara al futuro. En las entrañas de la guerra, en la tierra socavada por el hombre para ocultarse, se incubaba el hombre nuevo que vendría a derribar para siempre el orden burgués pletórico de afeminamientos. Años después, Jünger condensaría estas ideas en lo que puede nominarse como ontología del riesgo y del peligro:

Las fuentes de lo elemental son de dos especies. Por un lado están en el mundo, el cual es siempre peligroso aun en los momentos en que no sopla el viento. Y por otro lado se hallan en el corazón humano, el

${ }^{17}$ La experiencia de Jünger coincide con la del poeta simbolista Arthur Rimbaud, quien luego de alejarse de su amigo Paul Verlaine, emprendió un viaje a Africa en 1873 para dotar de emoción y aventuras a su vida. Tras su regreso a Francia, ya muy enfermo apenas si vivió unos meses de 1891.

Revista e Filosofia,v. 18 n.22, p. 111-146, jan./jun. 2006 
cual está siempre anhelando juegos y aventuras, odios y amores, triunfos y caídas, y en todo momento se siente necesitado de peligro y también de seguridad, y siempre consideraría, y con razón, que una situación que estuviese fundamentalmente asegurada sería una situación incompleta (JÜNGER, 1992, p. 56).

Norbert Elias sospecha de estas aseveraciones, sostiene que en el combate el excitante aniquilamiento del enemigo que abandona la trinchera precisaba de algunas técnicas para evitar que entre los soldados se propagase el miedo a la mutilación y a la muerte. Elias supone que los milicianos alemanes, a diferencia los pueblos primitivos, no estaban habituados a mantener luchas cuerpo a cuerpo. Por lo tanto, este proceder debió haber resultado más dificultoso entre hombres instruidos para fines civilizados en el seno de sociedades industriales. Siguiendo esta hipótesis, podría decirse que el rito comunitario narrado por Jünger sería una forma de superar las barreras internas (inhibiciones) mediante voces de aliento mutuo, la ingestión de alcohol y la entrega a una furia extrema, para lograr cumplir con el deber social del valor (ELAS, 1999, p. 251). Las afirmaciones de Elias desconocen dos datos que parecen al menos matizar sus conclusiones. Por un lado, la matanza perpetrada en la guerra no hacía indispensable la visualización de los enemigos desde cerca, el combate cuerpo a cuerpo era una situación excepcional, la muerte se administraba a través de máquinas, de manera distante, impersonal y abstracta. Por otro, las declaraciones del propio Jünger en su senectud plantean una excepción importante a la teoría desarrollista del proceso de civilización que sostiene Elias, según la cual el hombre sería efectivamente domesticado por las cadenas de interdependencia y por la cultura libresca, que Sloterdijk encuentra caduca luego de 1945 (SLOTERDIJK, 1999). Curiosamente, o quizá no tanto, Jünger leía unas páginas antes de entrar en combate y precisamente esas líneas eran las que le inspiraban la energía que demandaba la acción.

Ante aquel escenario mi visión de la guerra asumió la forma de un activismo heroico. Naturalmente, no se trata de simple militarismo, porque siempre, también en aquel entonces, he concebido mi vida como la vida de un lector antes que la vida de un soldado [...] fue sobre todo la lectura de algunos libros lo que me ofreció motivos para la acción. Cuando, en cambio, he creído extraer esos motivos de la realidad, he quedado profundamente decepcionado. Quiero decir que 
para mí el heroísmo nacía más de una experiencia literaria que de una efectiva y concreta posibilidad de vida [...] Me llevó al heroísmo la lectura de Orlando furioso de Ariosto. Aquellas palabras, aquellas rimas leídas durante las pausas entre un combate y otro fueron las que me motivaron (JÜNGER, 1998, p. 21-22).

Ciertamente, el caso de Jünger es ante todo atípico y aunque probablemente las lecturas complementaran el rito cuasi religioso y comunitario, no se debe olvidar que la religión tal como la conocemos en las variantes que más prosélitos han reclutado es el culto del libro. Además, los poemas homéricos, fundacionales para la lírica occidental, dedican casi por completo su extensión a narrar las peripecias de la guerra antigua. Jünger es, en último término, un artífice dotado de un virtuosismo literario extremo, capaz de resucitar las más antiguas fórmulas tornándolas propicias al contexto moderno.

El sentido estético que exhibe la obra de Jünger es básico para comprender los planteos éticos que desliza el autor. Las influencias del decadentismo decimonónico se tornan visibles en los pasajes dedicados a la relación que establece entre ética y estética. La influencia que sobre Jünger tuvieron escritores decadentistas como Wilde y Baudelaire ha sido destacada en otros trabajos. ${ }^{18}$ En ambos la idea de belleza aparece por encima de los preceptos morales, este concepto de la belleza que escapa a cualquier recusación ética fue conectado por estos escritores con una noción elitista de voluntad. Si bien Jünger renegaba del decadentismo, al modo que lo hacía Nietzsche, asimilaba totalmente los hechos estéticos a lo ético. En este marco, el triunfo de la voluntad y el espíritu sobre la razón, implicaba la alianza de la voluntad con un sentido estético inmanente. Lo bello se justifica a sí mismo, una vida estética valía más que la de mil seres aferrados a los valores morales muertos. En este código nada obstaculiza el despliegue del deseo, la moral es anulada y reemplazada por la belleza, aún aquella fundada en la estetización del horror y la violencia.

18 También Jorge Morales Aimar ha enfatizado las cercanías existentes entre Baudelaire y Jünger. Cfr. MORALES, Jorge Ernst Jünger: El mito como función política. Un análisis del libro El trabajador. Dominio y Figura. Seminario General, Facultad de Humanidades y Artes (FHyA), Universidad Nacional de Rosario (UNR), 2001. Del mismo autor La vida está en otra parte. Razón, ciudad y Naturaleza en Baudelaire, Zamiatin y Jünger. Seminario de Espacio y Sociedad, FHyA, UNR, 2005. 
Nosotros los jóvenes no nos podíamos permitir la décadence como la que a finales del siglo XIX se había permitido la generación francesa de Huysmans. La fatiga al anochecer es saludable, pero antes del mediodía es preocupante [... ] Nuestra actitud era la de quien quería reconocer con mirada desencantada la nueva realidad técnica y del trabajo y tomar parte en ella sin añoranzas nostálgicas ni proyecciones apocalípticas [...] volver a encontrar, en el mito o en la historia, una potencia que obrase como contrapeso del pesimismo. Tal como lo había dicho Nietzsche en Ecce Homo: "... soy un décadent: pero también soy su antítesis.Ver la relación entre ética y estética simplemente como una antítesis no es suficiente para mí. [... ] Por eso diría que la ética y la estética se encuentran y se tocan por lo menos en un punto: lo que es verdaderamente bello no puede no ser ético, y lo que es realmente ético no puede no ser bello (JÜNGER, 1998, p. 19; 23).

Aquí se expresa el sentimiento de un romanticismo resignado a afrontar el desencantamiento weberiano del mundo, pero que al mismo tiempo se encara con la tecnología moderna sin ambigüedades e intenta desentrañar su secreto, para obtener un nuevo punto de apoyo con miras a obrar. ${ }^{19}$ Los acontecimientos inquietantes y trágicos, con sus interpretaciones milenaristas o nostálgicas del pasado, que irrumpieron a principios del Siglo de las catástrofes (XX) - el paso del cometa Halley en 1910, el naufragio del Titánic en 1912 y la Guerra de 1914- poco pudieron hacer para arredrar a esta generación de jóvenes nacidos en el corazón de la pequeña burguesía. Precisamente, fue de estas experiencias que los jóvenes del frente extrajeron la materia prima para la construcción de sus reflexiones posteriores. Después de esos tres acontecimientos, el romanticismo se despojó para siempre de la mirada plañidera que sostenía al pastoralismo antiindustrialista, para fundirse en el fuego de la guerra con el acero, la máquina y la voluntad de poder.

Empero, esta aleación no podía lograrse sin mediar algunos recursos que reverenciaran lo nuevo (técnica) bajo las invocaciones (atributos sublimes) que usualmente se reservaban a lo viejo (naturaleza). Así, las metáforas que Jünger construye sobre la guerra en Tormentas de Acero emparientan, desde su título, el fenómeno tecnológico con el acon-

19 La Decadencia de Occidente de Spengler esta plagada de vaguedades en su posición respecto a la técnica. A punto tal que El hombre y la técnica es una especie de aclaración favorable sobre esta cuestión. SPENGLER, Oswald La decadencia de Occidente. Bosquejo de morfología de historia universal. Madrid: Espasa Calpe, 1976; El hombre y la Técnica..., cit. 
tecer natural. Una "barricada de artillería" era una "tormenta de hierro". Un avión bombardero era visto como un "buitre" que traza círculos sobre las tropas enemigas, que eran a su vez, "un enjambre de abejas". Algo similar ocurre en La Movilización Total y en El Trabajador:

Este espectáculo [el de la guerra] hace pensar en los volcanes que escupen al mismo tipo de lava, a través de la geografía y la historia humana, mientras que las regiones donde se desarrolla la actividad telúrica son diferentes.

Ya en la guerra del catorce hubo zonas de aniquilación cuyo aspecto sólo puede describirse si se acude a la comparación con las catástrofes de la naturaleza (JÜNGER, 1992a, p. 4;1992, p. 184).

Para Jünger participar en una guerra era análogo a encontrarse en las faldas de un volcán a punto de entrar en erupción. La guerra en tanto movimiento "...telúrico puso a prueba los cimientos de todos los edificios."(JÜNGER, 1992a, p. 9). En estas descripciones se percibe cómo lo propiamente humano e histórico es camuflado bajo metáforas que aluden a la naturaleza. ${ }^{18}$ La guerra no se estructura a partir de un conflicto de intereses nacionales concretos, por el contrario participan fuerzas difíciles de localizar y explicar, se trata de una batalla librada entre concepciones suprahistoricas como la "vida" y la "sangre". Jünger efectuó una operación de asimilación de la naturaleza en sus referencias sobre la técnica. Así, la técnica deviene en su prosa una segunda naturaleza inauténtica y artificial, y, por ese hecho, tanto más útil para fijar un principio de verdad metafísico.

En los párrafos que Jünger consagra a la Guerra, ésta se antropomorfiza para adoptar la figura de un padre dotado de subjetividad, asimismo, las cosas adquieren el lugar de los hombres. La guerra modela, cincela y endurece el cuerpo de sus hijos que forman la generación que contaría entre sus filas al hombre nuevo. "La guerra nos forjó y nos endureció en lo que ahora somos [...] mientras la oscilante rueda de la vida gire en nuestro interior, esta guerra seguirá siendo el eje alrededor del cual gira"(JÜNGER, 1997,p. 13).

20 Amén del recorrido simbólico que la naturaleza tiene en el pensamiento romántico alemán, cabe señalar que probablemente algunas de estas alusiones se deban a la formación universitaria de Jünger, quien entre 1923 y 1925 estudió zoología en Leipzig y cuyos intereses particularmente recayeron sobre la entomología. 
La guerra no es la declinación de occidente, como lo quisiera O. Spengler, antes bien es el signo inequívoco de un cambio cultural. Se trata del resurgimiento del barbarismo en pleno apogeo de "la iglesia popular del siglo XIX: el progreso."(JÜNGER, 1992, p.5). Norbert Elias llamaría a esto supresión o decurso invertido del proceso de civilización. ${ }^{21}$ No obstante, Jünger comprende la experiencia bélica en la dialéctica de la destrucción y la creación, como pensador afecto a las formulaciones nihilistas, estaba convencido de que para asistir al nacimiento del hombre nuevo debe completarse la destrucción del mundo burgués. La batalla como experiencia interior implica un proceso existencial cercano a la resurrección. El renacimiento se produce en los grandes cementerios que son los campos de batalla, pletóricos de esas fosas comunes llamadas trincheras. Los cuerpos esparcidos y la derrota alemana fueron trocados en la narrativa de Jünger en victoria. El escritor alemán no refiere a un triunfo política sino cultural, compuesto por la Gemeinschaft masculina y el hombre nuevo que la celebra con su valor y coraje, desconociendo la afectación de la sociabilidad burguesa.

La guerra se transforma en arte, en el marco de una filosofía que anticipadamente Walter Benjamin vinculó a la teoría de l'art pour l'art. ${ }^{22}$ La destrucción creadora es la obra faustica del combate y de la técnica.

A hora estamos escribiendo poesía sacada del acero y de la lucha por el poder en batallas donde los sucesos se mezclan con la precisión de las máquinas. En esas batallas en tierra, en agua y en aire hay una belleza que podemos prever. Allí se restringe la cálida voluntad de la sangre y luego se expresa a través del dominio de las maravillosas obras técnicas del poder(JÜNGER, 1997, p. 107).

La poesía de acero que canta a la guerra granjea para la tecnología y el poder de destrucción masivo los encantos de la belleza, en el marco de una estética masculina metálica, plenamente moderna y des-

21 CHARTIER, Roger "Elias, el proceso de civilización y barbarie", en: FINCHELSTEIN, Federico (ed.) Los alemanes, el Holocausto y la culpa colectiva. El debate goldhagen. Buenos Aires: Eudeba, 1999, pp. 174-204.

22 "Walter Benjamin lo dijo bien: Jünger transforma las tesis del arte por el arte mismo, en la de la producción por la producción y la destrucción por la destrucción misma. La guerra es su propio fin." HERF, Jeffrey El modernismo..., cit., p. 205. 
pojada de consideraciones morales. Benjamin intentó descosificar a la técnica, develar su secreto esencial: el ocultamiento de las relaciones humanas que la producen. ${ }^{23}$ Por el contrario, Jünger llegó a comparar a la tecnología hecha para la destrucción masiva con la obra de arte clásica, al mismo tiempo señaló que ambas cumplen en épocas diversas el mismo papel de distinción social aristocrática, la misma función de redención del aura.

Aviones, aeronaves, vapores de turbina, presas, ciudades mecanizadas, ejércitos motorizados, ésas son las cosas que forman la representación del dominio del trabajador; y la invitación a visitar esas instalaciones corresponde a la invitación a asistir a la opera italiana que el viajero distinguido recibía del príncipe absoluto(JÜNGER, 1992, p. 258).

En medio de las ráfagas de fuego, de la atmósfera del gas mostaza, del estruendo de las explosiones y del repiqueteo de las metrallas, Jünger cree percibir el buril que labra la placa de valores del hombre nuevo. Herramienta productora de un guerrero mecanizado a través del movimiento incesante de la guerra y el trabajo.

La generación de la Fronterlebnis fue capturada por la técnica, sus miembros estaban convencidos de que ella era la piedra angular para estetizar la política y para escapar de la crisis de declinación que embargaba a la cultura alemana y occidental de fin de siècle. Celebraban la emergencia de una forma de acero, consolidada por los rigores de las trincheras, un hombre cuyo cuerpo estaría completamente mecanizado, su rostro hecho de granito, sus ojos penetrantes y endurecidos por un sinfín de horrores devolverían el orden al "caos socialdemocrata-burgues de la República de Weimar "(JÜNGER, 1992, p. 21)24 Este hombre nuevo, con su cuerpo completamente sólido, sería inmune al dolor y a toda sensibilidad característica de los tiempos burgueses.

23 BENJAMIN, Walter "La obra de arte en la época de su reproductividad técnica", en: Discursos interrumpidos. Madrid: Taurus, 1987. Sobre esta temática puede consultarse también GONZÁLEZ, Horacio "Benjamin y el Fascismo", en: AA. VV. Sobre Walter Benjamin. Vanguardias, histórica, estética y literatura. Una visión latinoamericana. Buenos Aires, Alianza Editorial / Goethe-Institut, 1993, pp. 265-271.

24 "El orden es la imagen de la libertad reflejada en un espejo de acero. La obediencia lo que quiere decir el arte de oír- y el orden son la disponibilidad a ejecutar que cual rayo penetra en la copa y llega hasta las raíces.”. 
“La aceptación 'heroica' de la tormenta de acero [amor fati] acompaña a la capacidad de considerar nuestro propio cuerpo como una máquina que está más allá del placer, el dolor y la emoción( HERF, 1970, p. 171)." Mediante estas proclamaciones, el cuerpo humano se desharía de las sensaciones, adaptando las formas de un batallador perfecto, sin fisuras ni angustias ni placeres que obstaculizaran el mecanismo de la acción del trabajador-soldado, incardinado en la dialéctica creación-destrucción entendida como un género artístico.

No obstante la utopía del cuerpo mecanizado y de la Gemeinschaft de las trincheras no estaba desprovista de algunas aporías. En un mundo de trabajadores-soldados, dominados por el omnímodo Estado Total, en el que la planificación y el cálculo espiritualizado se enseñoreaban, Jünger, logró crear un espacio para el despliegue existencial del aventurero. A pesar de las aparentes contradicciones, estos argumentos son completamente coherentes con su pensamiento. Así como en la estrechez y el lodo sangriento de las trincheras, Jünger descubría un bálsamo que disolvía la seguridad burguesa - aunque la guerra fuera burguesa e interimperialista - , en la técnica total, que establecía la anulación de la voluntad, el escritor alemán concibe la manifestación de la voluntad de poder antiburguesa - aunque la tecnología también fuera burguesa 0 , al menos, estuviera amparada por el capitalismo.

El proceso racionalización y tecnificación absoluto, que durante la entreguerras parece alcanzar al cuerpo humano, es saludado con gran entusiasmo. El 'realismo heroico' de Jünger imaginaba en el mayor sometimiento del sujeto el camino hacia su liberación. La máquina, en este proceso, no era un mero instrumento exterior, se hallaba integrada a los músculos y nervios del trabajador-soldado. En definitiva, la técnica era un todo orgánico, que imbricado con el hombre engendraba belleza a través de su dominación. Sin embargo, Jünger estaba persuadido de que el trabajador sería capaz de dotar de alma a la máquina y para ello debía involucrarse, o mejor, entregarse por completo, ofrendando al mecanismo técnico todo su ser. En este sentido, la actitud del hombre frente a la máquina y la técnica debía ser equivalente a la del soldado ante la guerra: obediencia ciega, cemento de la comunidad y la dominación.

En todos los sitios donde el ser humano cae bajo la jurisdicción de la técnica se ve confrontado a una alternativa ineludible. $\mathrm{O}$ bien acepta los medios peculiares de la técnica y habla su lenguaje, o bien desapa- 
rece. Pero cuando alguien acepta esos medios, entonces se convierte [... ] no sólo en el sujeto de procesos técnicos, sino al mismo tiempo en el objeto. El empleo de los medios comporta un estilo de vida enteramente determinado, que se extiende tanto en las cosas grandes como en las cosas menudas del vivir. En modo alguno es, pues, la técnica un poder neutral, un almacén de medios eficaces o cómodos al que cualquiera puede recurrir a su antojo [... ] Lo que se esconde precisamente detrás de la apariencia de neutralidad es, antes bien, la lógica misteriosa y seductora con que la técnica sabe ofrecerse a los seres humanos, una lógica que se hace más y más evidente e irresistible a medida que va ganando totalidad el espacio de trabajo (JÜNGER, 1992, p. 156).

En definitiva la tesis central del libro El Trabajador sostiene que la técnica es la movilización del mundo por obra del trabajador, en una relación donde el hombre no aparece ni como creador ni como víctima de fuerzas técnicas exteriores o endemoniadas. En la relación hombretécnica / técnica-hombre, ambos términos son productos de energías superiores, incongnosibles. El trabajador es un tipo humano que concibe su reivindicación de la libertad como una demanda de trabajo y que posee un sentido para el nuevo lenguaje de mando. El trabajador, por lo tanto, despliega su dominio en todos los lugares donde presta servicio. En la era del trabajador el individuo no cuenta como valor aislado, sino como valor funcional, es decir, por la función que desempeña en tanto servicio prestado a la comunidad. Jünger además de asimilar el mundo del trabajo al proceso de la guerra ${ }^{23}$ entiende que la disciplina militar y su orden jerárquico son los únicos que pueden imperar en el mundo del trabajo: “... resulta perfectamente posible integrar al mundo del trabajo el concepto prusiano del deber."(JÜNGER, 1992, p. 71).

Este punto de vista se expresa con fuerza cuando Jünger describe las acciones y el funcionamiento del Barco de Guerra. El barco es la manifestación concreta de un cuantum de energía potencial técnica. Los seres humanos se integran a ese engranaje descomunal, funcional y cosificado. La nave de acero es, para Jünger, la manifestación de una vo-

25 "La guerra del catorce no representa desde luego, en la medida que pertenece al siglo $\mathrm{XX}$, una suma de guerras nacionales. Hay que considerarla, antes por el contrario, como un amplísimo proceso operativo en el cual la nación aparece en el papel de magnitud de trabajo. El esfuerzo nacional desemboca en una imagen nueva, desemboca en la construcción orgánica del mundo”. JÜNGER, Ernst El Trabajador..., cit., p. 145.

Revista e Filosofia,v. 18 n.22, p. 111-146, jan./jun. 2006 
luntad fría e inescrutable que hace de los hombres sus medios. Nótese que aquí se invierten los razonamientos instrumentales sobre la técnica. Justamente, es a través de los procesos exactos, subordinados y especializados que la máquina se apropia del hombre y que éste, a su vez, se vuelve capaz de infundirle espíritu a la técnica. La máquina domina en la utopía conservadora de la comunidad tecnológica (antes comunidad de las trincheras), el hombre nuevo se somete sin ambages, su destino, matemáticamente determinado, es aceptado con alegría (nuevamente amor fati). En esto consiste el 'realismo heroico', aplicable tanto al sometimiento del trabajador como del soldado.

En la era del trabajador el individuo burgués encuentra su ocaso, se disuelve en la nueva figura que primero lo subordina, para luego instarlo a su desaparición. El progreso de la forma a favor del movimiento elimina la personalidad individual y disuelve al ser en la masa. Entre más técnico se vuelve el mundo más se sujetan las tareas al movimiento de la máquina, por consiguiente más se reprime al individuo, en lo que podría llamarse disciplinamiento maquínico (GAUDEMAR, 1981).

Las grandes ciudades eran el teatro de este proceso de subordinación y desaparición de la burguesía. En los escritos de la segunda mitad de los años 1920s., Jünger observa a las metrópolis con cierta ambigüedad, aunque reconoce que son inamovibles y su desarrollo es deseable, algunas de las formas que reviste la vida cotidiana urbana le suscitan una sensación rayana en la fobia. La sombra de la guerra se proyectaba sobre las descripciones que Jünger esboza en torno a la tecnología, que era valorada como amenazante y hermosa. La belleza y el peligro de la máquina sacuden el alma de la pequeña burguesía alemana, la atemorizan. Jünger redescubre una pieza muy sugerente del rompecabezas de la cultura occidental: “... las ciudades se estaban volviendo más simples... más profundas... más civilizadas... es decir más bárbaras... de nuevo poseídas por la naturaleza."(JÜNGER, 1927, p. 6 apud HERF, 1998, p.211) Civilización y barbarie se encontraban y amigablemente departían frente a una taza en el café de la tecnología metropolitana. La técnica no implica la anulación de la barbarie, la alianza entre la idea de progreso y civilización se había despedazado definitivamente. La visión jüngeriana de la técnica (civilización-barbarie, seguridad-peligro) en entornos urbanos siempre se debate entre combinaciones inestables de fascinación sacro-heroica y repudio temeroso. Justamente, quien sólo encontraba emoción en la guerra, se hallaba desconcertado cuando el 
universo de la seguridad y la civilización (la ciudad) se trastrocaba en el teatro de la barbarie y lo indeterminado (la jungla) (SINCLAIR, 1985).

El 'susurro silbante del acero en el aire' es 'calmante y excitante'. El ruido de la calle tiene algo 'amenazador en extremo'. Un café callejero puede 'provocar una impresión diabólica', mientras que la alarma de un despertador recuerda la 'catástrofe'. Los anuncios de neón, un moderno bar, un filme estadounidense, son 'manifestaciones de una poderosa rebelión diabólica, cuyo espectáculo impregna al individuo de lujuria rabiosa y de una ansiedad aplastante'. El individuo se siente asombrado ante este espectáculo tecnológico 'donde todo se mueve suavemente como una niebla misteriosa o como un proceso milagroso(JÜNGER, 1998).

En los primeros años de la década de 1930, Jünger publicó libros sobre la irrupción de lo peligroso en la vida cotidiana: Uber die Gelhar y Der Gefäjrliche Augenblick, el último es una colección de fotografías que muestra momentos peligrosos de la vida diaria en las metrópolis europeas de entreguerras. Siguiendo estos textos, para 1930 ya no era necesario alistarse con los milicianos para salvarse del tedio burgués, la nueva tecnología y la irrupción de las masas - circulación de automóviles, aviones y las manifestaciones populares- perturbaban enormemente la seguridad de las ciudades. Las fotografías de Jünger poseen el efecto de un placebo anestésico. La fotografía, como técnica de representación de la realidad, se distancia del sufrimiento humano. La cámara es un ojo mecánico, sin relación con los sentimientos y las emociones, capaz de simbolizar, de tornar estético, de poner nombre al movimiento inexplicable e incontrolable que produce el reflejo fóbico. ${ }^{26}$ La simbolización por el lenguaje o la imagen tranquiliza al espíritu, convierte al mundo indeterminado y hostil en una postal visualmente abarcable y culturalmente controlable.

La cámara es un instrumento para tomar una instantánea del momento en que aparece el peligro. Los libros de fotografías de Jünger en particular Un Encuentro Peligroso ${ }^{27}$ [Der gefährliche Augenblick], pletórico de fotos de barcos que se hundían, automóviles que chocaban,

${ }^{26}$ DARWIN, Charles La expresión de las emociones en los hombres y los animales. Valencia: Sempe, 2 vs., s/f. [The expression of emotions in man and animals, $1^{\circ}$ ed. 1872]. ${ }^{27}$ JÜNGER, Ernst Un encuentro peligroso. Barcelona: Planeta, 1997 (Con CD-Rom).

Revista e Filosofia,v. 18 n.22, p. 111-146, jan./jun. 2006 
aeroplanos que se desplomaban, terremotos y manifestaciones callejeras, narran esta indeterminación temor-heroísmo. Aunque si no se ha de acometer una tarea que arredra a la mayoría no existe heroísmo posible. La fotografía al alejarse del campo emocional y reproducirse hasta el hartazgo - en su esencial reproductividad técnica- amortigua, y hasta anula, el choque que provoca la realidad, al mismo tiempo que es capaz de transformar escenas de sufrimiento en cuadros estéticamente reputados.

Benjamin bordó sobre la idea de que la protección contra los estímulos externos es tan importante para la prevención de la ansiedad como la percepción inicial de esos estímulos. Tales estímulos plantean la amenazas de choques para el sistema psíquico. Entre más claramente los registre la conciencia menos probable es que tengan un efecto traumático. La terapia psicoanalítica es un procedimiento para la reducción de estos choques mediante la expansión del alcance de la conciencia sobre el inconsciente. Otro método para la reducción del impacto de los choques culturales consiste en ubicar el estímulo en cuestión en un punto particular del tiempo y en la conciencia, así sea a costa de perder la plenitud y la profundidad de la experiencia [... ] esto es precisamente lo que explica el interés sobre la fotografía de Jünger. Es un mecanismo de defensa contra la ansiedad provocada por los choques de la cultura moderna y del cambio social tecnológico (HERF, 1998, p. 214-215).

El romanticismo antitecnológico desaparecía del campo cultural alemán, las juventudes, que en pocos años fueron hitlerianas, no necesitaban de ideologías que hicieran posible la superación de la tecnología a través de metáforas pastoriles y saudades del pasado, antes bien se intentaba dar con las fórmulas que consiguieran reunir (simbiosis) a los organismos hombre y técnica. La obra de la prosa jüngeriana había sido completada, El Trabajador era discutido en varias universidades (entre ellas la de Friburgo, donde Heidegger le dedicó algunos seminarios), también ciertos políticos nacionalsocialistas le prestaron particular atención a sus dos últimos capítulos: "El tránsito de la democracia liberal al Estado de trabajo" y "El relevo de los contratos sociales por el plan de trabajo" (JÜNGER, 1992, p. 224-274). 


\title{
Conclusiones
}

\begin{abstract}
“Entre nosotros ha cobrado vida una tendencia a despreciar la razón y la ciencia' eso es un falso retorno a la Naturaleza. Lo que importa no es despreciar el intelecto, lo que importa es someterlo. La técnica y la Naturaleza no son antitéticas - el sentirlas de ese modo es una señal de que la vida no está en orden. El ser humano que intenta disculpar su propia impotencia hablando de la falta de alma de sus medios se semeja al ciempiés de la fábula, condenado a la inmovilidad porque se dedicaba a contar las patas que tiene"(JÜNGER, 1992, p. 187).
\end{abstract}

En este trabajo he intentado mostrar las formas en las que Ernst Jünger concibió la relación entre el sujeto y la técnica desde el inicio de la década de 1920 hasta 1933. El propósito ha sido vincular las formas históricas que animaron el pensamiento de Jünger como una alternativa al romanticismo clásico de tono pastorialista. En particular, la labor de los escritos de Jünger fue introducir a la tecnología con una valoración positiva en el repertorio de los símbolos trascendentales del conservadurismo cultural alemán. A fin de ilustrar estas cuestiones, se ha privilegiado un enfoque centrado en las peculiaridades del capitalismo alemán y la incidencia que éste tuvo sobre el campo cultural, del mismo modo se ha mostrado cómo la Gran Guerra operó como proceso catalítico de ciertas tendencias anti-humanistas que venían desarrollándose desde el final del siglo XIX.

E. Jünger inicia la escritura de su obra durante la Guerra, el mayor mérito de este trabajo es su intento de comprender un mundo que después de 1914 no volvería a ser igual. El otro aporte fundamental es el temprano reconocimiento del predominio técnico sobre los fenómenos sociales. Si bien la técnica es comprendida como una entidad metafísica, allende las relaciones sociales que la producen, y el hombre es considerado como un trabajador-soldado, un guerrero mecanizado por el rigurosidad del ritmo fabril, la detección de estos fenómenos señala nuevas condiciones de visibilidad para la weltanschaug del conservadurismo alemán de entreguerras. Trazando, además, los componentes políticos básicos que dio a luz la década de 1930.

Por otra parte, Jünger advierte que los procedimientos vinculados al trabajo, durante la primera mitad del siglo XX, se encaminaban hacia una transformación que los convirtió en una substancia total que 
no dejaba espacio ni tiempo sin alcanzar. Su despliegue se llevó a cabo a partir de una férrea disciplina que era solicitada y disfrutada por aquellos que eran su objeto: los jóvenes trabajadores(JÜNGER, 1992, p. 224). El trabajo se amalgamó a la técnica y forjó un nuevo tipo humano, cuya figura estaba despojada de peculiaridades burguesas y se integraba con la totalidad. El trabajador, prohijado por el sometimiento militar-fabril, dinamizaba una relación simbiótica con la técnica que movilizaba al mundo, transformándolo en energía a partir de un proceso incesante. La técnica contribuía al dominio del hombre y del mundo, al mismo tiempo el hombre le entregaba su alma a la técnica. La verdad de este conglomerado de fuerzas en tensión era inaccesible. El principio de causalidad de la figura, en la que se daban cita profusión de fenómenos, era siempre diferido por Jünger a una instancia suprahistórica, vinculada a un ser inmóvil y a fuerzas telúricas difíciles de precisar. ${ }^{28}$

En con secuencia, el ambiente que requería la feliz imbricación del hombre, el trabajo y la técnica, en buena parte, dependía de que el hombre dejara de ser humano, en el sentido humanista y antropocéntrico del término, y se mecanizara. Además, la máquina debía adquirir espíritu, cosa que sólo podía infundirle el trabajador, pero el trabajador ya no era un hombre. Semejante aleación podía lograrse únicamente, tras la desaparición de la civilización burguesa, en los talleres del Estado Total, una forma de poder político que estaba destinada a engullir completamente a la sociedad civil. Jünger consideraba que constituía un absurdo mantener la división liberal entre Sociedad Civil y Estado, ya que la guerra de 1914 había demostrado que el futuro sería dominado por la movilización total. ${ }^{29}$ En el marco de la movilización total, requerida por la guerra total, no era posible diferenciar al Estado de la sociedad, a los

28 “... con referencia a la figura es preciso liberarse del pensamiento de la evolución [...] Una figura es, y ninguna evolución la acrecienta o la aminora. De ahí que la historia de la evolución no sea la historia de la figura sino, a lo sumo, su comentario dinámico [... ] La figura del ser humano era antes del nacimiento y será después de su muerte y de igual manera una figura histórica es, en lo más hondo, independiente del tiempo y de las circunstancias en las que parece surgir [... ] La historia no hace brotar figuras es ella la que cambia con la figura." JÜNGER, Ernst El Trabajador..., cit., p. 83.

29 Es notable el hecho de que sea precisamente la guerra la que termina con esta división. Jünger creía que la guerra de 1914 era un acontecimiento cuyas consecuencias serían aún más importantes que las de la Revolución Francesa, probablemente, estas consideraciones respondieran a una cierta afinidad ideológico-política con los distintos fenómenos históricos. Cfr. Jünger, Ernst El Trabajador..., cit., p. 149. 
soldados de los trabajadores civiles, a la economía de guerra de la doméstica, al frente de la retaguardia. En cierta medida, Jünger propone al Estado autoritario, desligado de la mediaciones parlamentarias y reformistas, como un preludio adecuado para la obra de su amigo Carl Schmitt y, también, del régimen Nazi al cual la publicación de El trabajador anticipa en pocos meses. Si bien la obra de Jünger encastraba a la perfección con el nacionalsocialismo, su autor jamás se afilió al NSDAP y ya avanzado el régimen mostró su desacuerdo con el totalitarismo hitleriano en su novela Sobre los acantilados de Mármol (JÜNGER, 1990). En 1939, tras la publicación de este libro, que fue rápidamente prohibido, su acérrimo enemigo Joseph Goebbels dijo: “...Jünger antes escribía filosofía, ahora sólo literatura."

La obra de Jünger, en sentido político, puede dividirse antes y después del nacionalsocialismo, pero sus concepciones filosóficas más fundamentales se han mantenido relativamente constantes durante el extendido período de una centuria.

Rosario, 29 de octubre de 2005

\section{Referências}

ANDREASSI CERI, Alejandro. Arbeit Macht Frei: El trabajo y su organización en el fascismo (Alemania e Italia). Barcelona: El Viejo Topo, 2004.

BAUDELAIRE, Charles. Los paraísos artificiales. Editorial Hispano Americana, s/f.

BENJAMIN, Walter. La obra de arte en la época de su reproductividad técnica. En: Discursos interrumpidos. Madrid: Taurus, 1987.

BENJAMIN, Walter. Teorías del fascismo alemán. En: Para una crítica de la violencia y otros ensayos. Madrid: Taurus, 1991. p. 55.

BERMAN, Marshall. Todo lo sólido se desvanece en el aire: La experiencia de la modernidad. Buenos Aires: Siglo XXI, 1989.

BERNAL, J. Science in history. Nueva York: C. A. Watts, 1965.

CHARTIER, Roger. Elias, el proceso de civilización y barbarie. En: FINCHELSTEIN, Federico (ed.) Los alemanes, el Holocausto y la culpa colectiva: el debate goldhagen. Buenos Aires: Eudeba, 1999. p. 174-204.

Revista e Filosofia,v. 18 n.22, p. 111-146, jan./jun. 2006 
CLAUSEWITZ, Karl Von. De la Guerra. Buenos Aires: Rescates Need, 1998.

ELIAS, Norbert. La exaltación de la guerra en la literatura de la República de Weimar (Ernst Jünger), En: . Los alemanes. México: Instituto Mora, 1999. p. 251.

ELAS, Norbert. Sociogénesis de la oposición entre «cultura»y «civilización»en Alemania. En:

El proceso de civilización: investigaciones sociogenéticas y psicogenéticas. México: Fondo de Cultura Económica, 1989. p. 57-94.

GAUDEMAR, Jean-Paul. La movilización general. Madrid: La Piqueta, 1981.

GONZÁLEZ, Horacio. Benjamin y el Fascismo. En: AA. VV. Sobre Walter Benjamin. Vanguardias, histórica, estética y literatura: una visión latinoamericana. Buenos Aires: Alianza: Goethe-Institut, 1993. p. 265-271.

GORZ, André. Adiós al proletariado (Más allá del socialismo). Barcelona: El Viejo Topo, 2001.

HAECKEL, Ernst. Freedom in science and teaching. [S.l.]:University Press of the Pacific, 2003.

HERF, Jeffrey. El modernismo reaccionario: Tecnología, cultura y política en Weimar y el Tercer Reich. México: Fondo de Cultura Económica, 1998.

JUNGER, Ernst La Movilización Total. Revista de la UNAM, p. 8, marzo, 1992.

JÜNGER, Ernst. El Trabajador. Dominio y Figura. Barcelona: Tusquets, 1992.

JÜNGER, Ernst. La Guerre comme expérience intérieur. París: Christian Burgois, 1997.

JÜNGER, Ernst. Sobre los acantilados de mármol. Barcelona: Destino-Libro, 1990. 185 p.

JUNGER, Ernst. Corazón Aventurero. Barcelona: Tusquets, 1998.

JÜNGER, Ernst. Juegos Africanos. Madrid: Guadarrama, 1970. 
JUNGER, Ernst. Los titanes venideros. Ideario último recogido por A. Gnoli y F. Volpi. Barcelona: Península, 1998.

JÜNGER, Ernst. Nationalismus und Modernes Leben. Arminius, n. 8, p. 6,1927.

JUNGER, Ernst. Tempestades de acero. Barcelona: Tusquets, 1993.

JÜNGER, Ernst. Un encuentro peligroso. Barcelona: Planeta, 1997.(Con CD-Rom).

LÖWY, Michael. Para una sociología de los intelectuales revolucionarios: La evolución política de Lukács 1909-1929. México: Siglo XXI, 1978. p. 25;31; 35.

MANN, Thomas. Schopenhauer, Nietzsche, Freud. Madrid: Alianza, 1990. $202 \mathrm{p}$.

MARINETTI, Filippo Tommaso. Manifeste futuriste. Le Figaro, 20 fev.1909.

MAYER, Arno. Visión del mundo: socialdarwinismo, Nietzsche, la Guerra. En: en la Persistencia del Antiguo Régimen. Madrid: Alianza, 1986. p.252;263

REMARQUE, Enrich-María. Sin novedad en el frente. Buenos Aires: Obris, 1985.

RICHTA, Radovan. La civilización en la encrucijada. México: Siglo XXI, 1971.

SIMMEL, Georg. Filosofía del dinero. Madrid: Instituto de Estudios Políticos, 1977. $661 \mathrm{p}$.

SIMMEL, Georg. Las grandes urbes y la vida del espíritu. En: El individuo y la libertad: Ensayos de crítica y de cultura. Barcelona: Península, 1986. p. 258.

SINCLAIR, Upton. La Jungla. Buenos Aires: Orbis, 1985. 2 v.

SLOTERDIJK, Peter. Reglas para un Parque Humano. Una respuesta a la Carta sobre el Humanismo. En: SIMPOSIO INTERNACIONAL SOBRE LA FILOSOFÍA EN EL FINAL DEL SIGLO, Baviera, 1999. Baviera:Castillo de Elmau, 1999.

Revista e Filosofia,v. 18 n.22, p. 111-146, jan./jun. 2006 
SPEER, Albert. Memorias: Hitler y el Tercer Reich vividos desde dentro. Barcelona: Plaza y Janes, 1974.

SPENCER, Herbert. El Individuo contra el Estado. Madrid: Orbis, 1984. SPENGLER, Oswald. El hombre y la Técnica. Buenos Aires: Austral, 1947.

SPENGLER, Oswald. La decadencia de Occidente: bosquejo de morfología de historia universal. Madrid: Espasa Calpe, 1976.

TEICH, Mikulás. La revolución científico-técnica: ¿Un acontecimiento histórico en el siglo XX? En: POTER, Roy y TEICH, Mikulás. La Revolución en la Historia. Barcelona: Crítica, 1990.

TÖNNIES, Ferdinad. Comunidad y Sociedad. Buenos Aires: Losada, 1947.

TRAVERSO, Enzo. La violencia nazi: una genealogía europea. Buenos Aires: Fondo de Cultura Económica, 2002.

ZAMIATIN, Evgeni. Nosotro. Buenos Aires: CEAL, 1903. p. 29. 